\title{
A Case of Bilateral Extracranial Internal Carotid Artery Dissection Due to the Helmet Strap After Motorcycle Crash
}

\author{
Sara Gioia, MD, * Lisa Franceschetto, $†$ Massimo Lancia, MD, * Mauro Bacci, MD, * and Fabio Suadoni, MD $\neq$
}

\begin{abstract}
The authors report a case of a man who developed stroke symptoms a few days after a road accident on his motorcycle. Radiographic examinations revealed the presence of bilateral dissection of the extracranial internal carotid arteries with signs of involvement of the brain parenchyma.

The location, timing, and presentation lead to the conclusion that the carotid lesions were secondary to the motorcycle collision; in particular, we suppose that it is due to the pressure exerted by the helmet strap worn. Although helmets have undoubtedly prevented serious injuries, this report highlights that the helmets themselves may cause injuries, especially to cervical soft tissues and vessels.
\end{abstract}

Key Words: arterial dissection, helmet injury, traumatic dissection, traffic injuries

(Am J Forensic Med Pathol 2019;40: 153-155)

$\mathrm{O}$ n July 18,1986 , Italy introduced the mandatory use of helmets for minors and adults with motorcycles with an engine displacement of more than $50 \mathrm{~mL}$ (Law, January 11, 1986, no. 3, articles 1-3). In 1999, another law was approved (Law no. 472, article 33), then enacted on March 30, 2000, which extended the obligation to adults with motorcycles with an engine displacement of less than $50 \mathrm{~mL}$. The Italian highway code punishes with an administrative sanction $(€ 80-€ 323)$ those who do not wear helmets when riding motorcycles.

These laws have greatly reduced the impact of head injuries and hospital admissions secondary to road accidents in Italy, consistent with the rest of the world, where similar laws were passed. ${ }^{1,2}$ By 2020, road traffic injuries are expected to be the third leading cause of death and disability worldwide. ${ }^{3}$

In motorcycle crashes, head and neck injuries are the leading cause of death, although a significant percentage of deaths are also due to injuries of the chest and the abdomen. In addition, for the past decades, the number of fatal injuries related to the use of 2-wheeled motor vehicles (eg, mopeds) in Italy has been higher compared with other industrialized countries. It is likely that many of these fatalities may be preventable, particularly head injuries, simply by wearing a helmet. ${ }^{4}$

Studies have undoubtedly shown that helmets are useful and essential devices and have reduced the rates of death and serious head injuries. ${ }^{5}$ However, several cases have also been described, in the literature, where the safety devices have actually caused damage to the wearer. For example, cases of fracture of the hyoid

Manuscript received October 15, 2018; accepted November 17, 2018.

From the *Section of Legal Medicine, and $\dagger$ School of Medicine, University of Perugia, Perugia; and $₫$ Section of Legal Medicine, Hospital of Terni, Terni, Italy.

The authors report no conflict of interest.

Reprints: Massimo Lancia, MD, Section of Legal Medicine, University of Perugia, P.zza Lucio Severi, 106123 Perugia, Italy. E-mail: massimo. lancia@unipg.it.

Copyright (C) 2019 Wolters Kluwer Health, Inc. All rights reserved.

ISSN: 0195-7910/19/4002-0153

DOI: $10.1097 /$ PAF.0000000000000458 bone, thyroid cartilage fracture, and skull base fracture have been described because of the thrust of the helmet strap on the neck during impact. ${ }^{6-8}$ Even cases of decapitation (complete and incomplete) have been described. ${ }^{9,10}$ In the present case, a motorcyclist who developed a bilateral internal carotid artery dissection as a result of a road accident is described.

\section{CASE REPORT}

In late July, a 36-year-old helmeted male driver experienced a traffic accident while riding his scooter. It was raining and he lost control of the vehicle while taking a corner, and then, he fell and rolled on the asphalt; he did not report head trauma. The traffic police report affirmed that he was speeding.

He was immediately transported with an ambulance to the emergency department, where he was found alert and conscious, without amnesia. The patient complained of pain in the dorsal spine and denied significant medical illnesses including connective tissue disease. The physical examination results revealed only an abrasion of the nasal pyramid, a large graze of the anterior region of the thorax and abdomen, and multiple abrasions in the upper and lower limbs without other significant findings. He underwent computed tomography (CT) scan of the chest and abdomen, which documented multiple bilateral areas of pulmonary parenchymal hemorrhagic contusion. He was admitted to the intensive care unit where he underwent conservative therapy until discharge approximately 5 days later.

Two days after discharge, the patient was transported to the same emergency department for a confused state. The patient appeared restless, disorientated, and aphasic.

He underwent cerebral CT that failed to show evidence of intracranial hemorrhages and focal cerebral parenchymal changes (strokes). He was admitted to the neurology department and underwent a Doppler ultrasound examination of the supra-aortic trunks, which revealed bilateral dissections of the internal carotid arteries with occlusion. One week later, a cerebral magnetic resonance imaging with angiographic sequences showed areas with characteristics of acute and subacute ischemic infarcts (stroke) in the right corticalsubcortical region at the border between the territory of the Sylvian artery and of the upper cerebral artery and confirmed bilateral stenosis from dissection of the extracranial internal carotids. Four days after the magnetic resonance imaging, an angio-CT scan (Figs. 1, 2) confirmed the presence of bilateral dissection of the extracranial internal carotids: the right extracranial internal carotid distal tract had a pseudoaneurismatic dilatation of the maximum diameter of approximately $7 \mathrm{~mm}$ and sagittal extension of approximately $1.5 \mathrm{~cm}$ with severe stenosis, and the left showed stenosis at the level of the middle third extracranial region.

Throughout the hospitalization, the patient was treated with supportive therapy, including mannitol, sodium heparin, and warfarin.

He was discharged approximately 2 weeks after his secondary presentation or nearly 3 weeks after the incident. Subsequent 


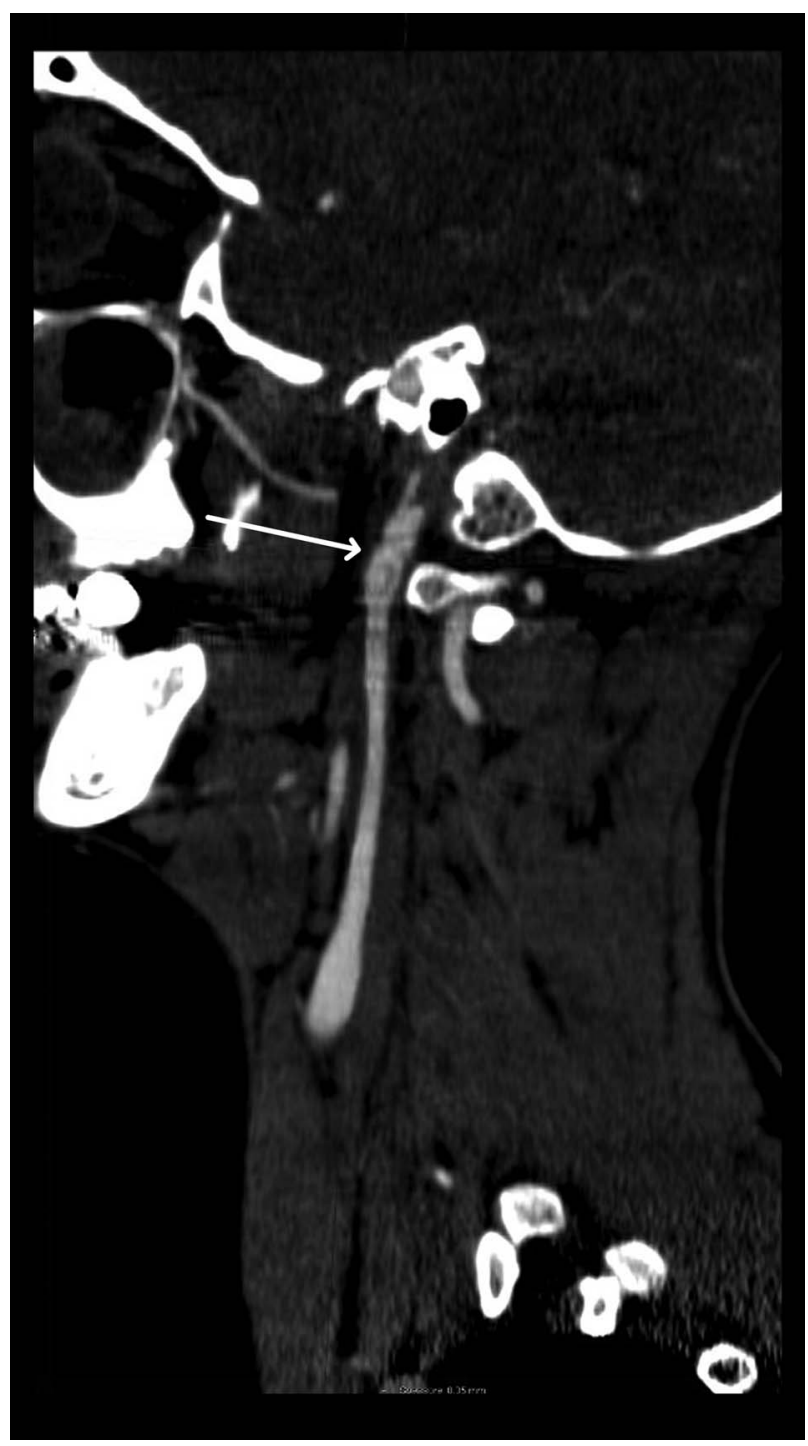

FIGURE 1. Cranial tomography showing right extracranial internal carotid dissection.

follow-up documented the clinical resolution without significant neurological sequelae.

\section{DISCUSSION}

Carotid artery dissection is the result of blood entering the media through a tear in the intima and is a common cause of stroke in young patients $(20 \%-25 \%$ of strokes in patients younger than 45 years), but it may occur at any age. ${ }^{11}$

Seventy percent of patients with carotid arterial dissection are between the ages of 35 and 50 years, with a mean age of 47 years. ${ }^{12}$

Clinically, symptoms may include loss of consciousness, hemiparesis, aphasia, and Horner syndrome and typically occur after an interval of hours to days.

Internal carotid dissection may be spontaneous, iatrogenic, or traumatic.

Spontaneous carotid dissection may be caused by hereditary connective tissue disorders, such as the following: Marfan syndrome, Ehlers-Danlos syndrome, autosomal dominant polycystic kidney disease, pseudoxanthoma elasticum, fibromuscular dysplasia, and osteogenesis imperfecta type I. ${ }^{13}$
Iatrogenic dissection is usually caused by neuro interventional procedures. ${ }^{14}$

The most common causes of traumatic dissections are motor vehicle accidents, sport-related, strong coughing or nose blowing, and chiropractic manipulation ${ }^{15-17}$; in addition, lengthy telephone conversations have been described as a risk factor, where a prolonged lateral flexion of the head may cause the dissection of the carotid artery. ${ }^{18}$

Two main mechanisms have been described as the cause of traumatic carotid artery dissections. The first one is the hyperextension and rotation of the neck that force traction on the internal carotid artery as it crosses the transverse processes of the second and third cervical vertebrae; the intima, being the least elastic layer of the arterial wall, tears under these forces. The second one is the abrupt full flexion of the neck, which may directly compress the internal carotid artery between the angle of the mandible and upper cervical vertebrae; this causes transmural crush damage. ${ }^{19}$

Traumatic carotid artery injury may not be associated with evidence of external injury and initially may go undetected or may be misinterpreted in the setting of associated neck or head

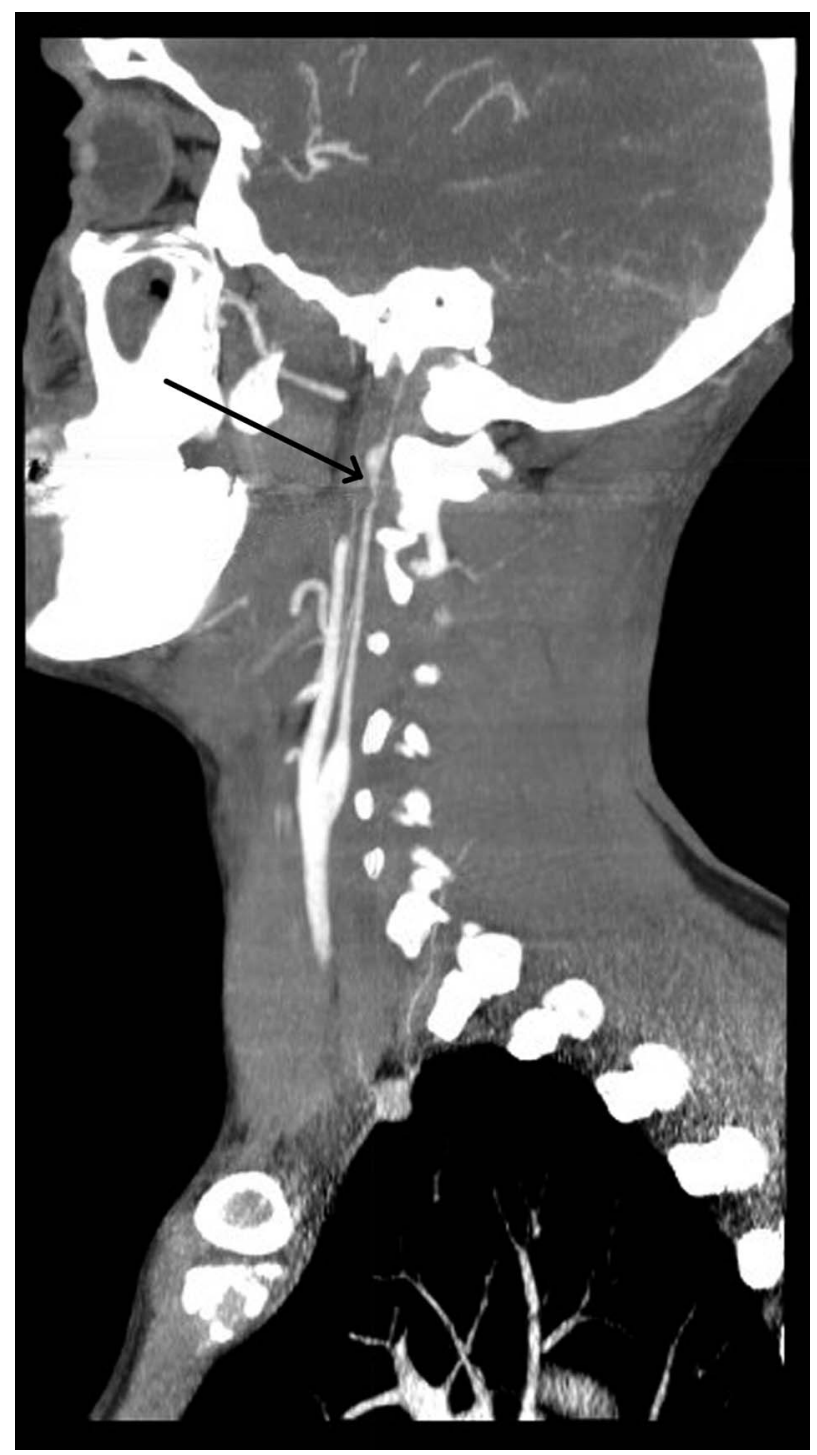

FIGURE 2. Cranial tomography showing left extracranial internal carotid dissection. 
trauma. ${ }^{20}$ In our case report, the patient lost control of his motorcycle while taking a corner too fast and then fell down. The location, timing, and presentation lead to the conclusion that the carotid lesions were secondary to the motorcycle collision.

In this particular case, the forces involved in the injury were probably the hyperextension and the rotation of the neck. However, the compressive force exerted on the soft tissues of the neck by the helmet strap cannot be ruled out as an alternative or concurrent cause of injury. Traumatic dissection of the cervical internal carotid artery due to compression by the strap has been previously described: Doi et $\mathrm{al}^{21}$ presented a case of a 21 -year-old man who fell off his motorcycle and struck his head at the right parietal region. He lost consciousness and developed left hemiparesis 2 hours after being admitted to an emergency department. Cerebral angiography revealed dissection of the right cervical internal carotid artery. The authors conclude that if the helmet strap is fixed around the neck, it can cause carotid artery injury during an accident, so the helmet strap should be fixed firmly at the chin. ${ }^{21}$

It is hypothesized that a helmet belt fastened too loose on the neck may have caused, during the impact, an excessive displacement of the helmet with great compression force of the belt on the soft cervical tissues.

Indeed, the malposition of the helmet, in the event of an accident, could cause the displacement of the strap from the chin to the neck, thereby producing compressive forces on the neck determined by the traction of the weight of the helmet itself.

\section{CONCLUSIONS}

In conclusion, because helmet use became mandatory, there has been a great reduction in mortality and morbidity related to road accidents.

However, as reported in literature and explained in this case report, sometimes, helmets are the sole or contributory cause to various types of injuries, much like airbags and seatbelts in motor vehicles. Moreover, malposition of the helmet cannot be entirely excluded as a cause of the injury.

It is important for forensic practitioners to understand the dynamics of collisions and the injuries seen to correctly educate their patients and the public at large about the correct usage of such safety devices in an effort to prevent further injury.

\section{REFERENCES}

1. Liu BC, Ivers R, Norton R, et al. Helmets for preventing injury in motorcycle riders. Cochrane Database Syst Rev. 2008;1:CD004333.

2. Abbas AK, Hefny AF, Abu-Zidan FM. Does wearing helmets reduce motorcycle-related death? A global evaluation. Accid Anal Prev. 2012;49: 249-252.
3. Derrick AJ, Faucher LD. Motorcycle helmets and rider safety: a legislative crisis. J Public Health Policy. 2009;30(2):226-242.

4. La Torre G, Van Beeck E, Bertazzoni G, et al. Head injury resulting from scooter accidents in Rome: differences before and after implementing a universal helmet law. Eur J Public Health. 2007;17(6):607-611.

5. Khor D, Inaba K, Aiolfi A, et al. The impact of helmet use on outcomes after a motorcycle crash. Injury. 2017;48(5):1093-1097.

6. Kuo LC, Lin HL, Chen CW, et al. Traumatic hyoid bone fracture in patient wearing a helmet: a case report. Am J Emerg Med. 2008;26(2):251.e1-251.e2.

7. Ostby ET, Crawley BK. Helmet clasp cracks larynx? A case series and literature review. Ann Otol Rhinol Laryngol. 2018;127(4):282-284.

8. Cooter RD, David DJ, McLean AJ, et al. Helmet-induced skull base fracture in a motorcyclist. Lancet. 1988;1(8577):84-85.

9. Gioia S, Suadoni F, Carlini L, et al. An unusual autopsy case of incomplete decapitation of a motorcyclist with herniation of thoracic organs through a helmet-related neck wound. Am J Forensic Med Pathol. 2013;34(4): 325-327.

10. Zoja R, Gentile G, Giovanetti GF, et al. Death by complete decapitation of motorcyclist wearing full face helmet: case report. Forensic Sci Int. 2011; 207(1-3):e48-e50.

11. Kumar V, Abbas AK, Fausto N, et al. Robbins and Cotran pathologic basis of disease. W B Saunders Co; 2005: ISBN:0721601871.

12. Cruciata G, Parikh R, Pradhan M, et al. Internal carotid artery dissection and pseudoaneurysm formation with resultant ipsilateral hypoglossal nerve palsy. Radiol Case Rep. 2017;12(2):371-375.

13. De Bray JM, Baumgartner RW. History of spontaneous dissection of the cervical carotid artery. Arch Neurol. 2005;62(7):1168-1170.

14. Paramasivam S, Leesch W, Fifi J, et al. Iatrogenic dissection during neurointerventional procedures: a retrospective analysis. $J$ Neurointerv Surg. 2012;4(5):331-335.

15. Haneline MT, Rosner AL. The etiology of cervical artery dissection. J Chiropr Med. 2007;6(3):110-120.

16. Thanvi B, Munshi SK, Dawson SL, et al. Carotid and vertebral artery dissection syndromes. Postgrad Med J. 2005;81(956):383-388.

17. López-Sánchez M, Ballesteros-Sanz MA, Pérez-Ceballos A, et al. Traumatic dissection of the internal carotid artery by a safety belt: a report of two cases[in Spanish]. Med Intensiva. 2009;33(7):353-357.

18. Mourad JJ, Girerd X, Safar M. Carotid-artery dissection after a prolonged telephone call. N Engl J Med. 1997;336(7):516.

19. Lee WW, Jensen ER. Bilateral internal carotid artery dissection due to trivial trauma. J Emerg Med. 2000;19(1):35-41.

20. Opeskin K. Traumatic carotid artery dissection. Am J Forensic Med Pathol. 1997;18(3):251-257.

21. Doi A, Deguchi J, Yamada M, et al. Traumatic internal carotid artery dissection due to compression by a helmet strap [in Japanese]. No Shinkei Geka. 2004;32(12):1279-1282. 